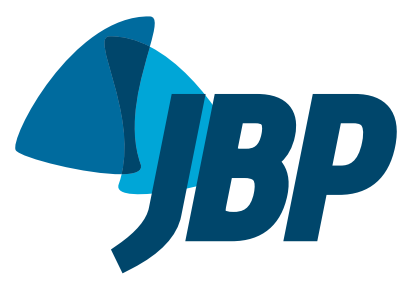

1. Laboratório de Pesquisa em Fisioterapia Pulmonar - LFIP - Departamento de Fisioterapia, Universidade Estadual de Londrina - UEL - Londrina (PR) Brasil.

2. Universidade Norte do Paraná, Londrina (PR) Brasil.

Submitted: 13 July 2016

Accepted: 14 April 2017

Study carried out in the Laboratório de Pesquisa em Fisioterapia Pulmonar LFIP - Departamento de Fisioterapia, Universidade Estadual de Londrina - UEL - and at the Centro de Pesquisa em Ciências da Saúde, Universidade Norte do Paraná, Londrina (PR) Brasil.

\section{Can the six-minute walk distance predict the occurrence of acute exacerbations of COPD in patients in Brazil?}

Fernanda Kazmierski Morakami', Andrea Akemi Morita', Gianna Waldrich Bisca', Josiane Marques Felcarr,2, Marcos Ribeiro', Karina Couto Furlanetto', Nidia Aparecida Hernandes ${ }^{1}$, Fabio Pitta ${ }^{1}$

\begin{abstract}
Objective: To evaluate whether a six-minute walk distance (6MWD) of $<80 \%$ of the predicted value can predict the occurrence of acute exacerbations of COPD in patients in Brazil over a 2-year period. Methods: This was a retrospective cross-sectional study involving 50 COPD patients in Brazil. At enrollment, anthropometric data were collected and patients were assessed for pulmonary function (by spirometry) and functional exercise capacity (by the 6MWD). The patients were subsequently divided into two groups: $6 \mathrm{MWD} \leq 80 \%$ of predicted and $6 \mathrm{MWD}>80 \%$ of predicted. The occurrence of acute exacerbations of COPD over 2 years was identified by analyzing medical records and contacting patients by telephone. Results: In the sample as a whole, there was moderate-to-severe airflow obstruction (mean $\mathrm{FEV}_{1}=41 \pm 12 \%$ of predicted) and the mean 6MWD was $469 \pm 60 \mathrm{~m}$ ( $86 \pm 10 \%$ of predicted). Over the 2-year follow-up period, 25 patients (50\%) experienced acute exacerbations of COPD. The Kaplan-Meier method showed that the patients in whom the 6MWD was $\leq 80 \%$ of predicted were more likely to have exacerbations than were those in whom the 6MWD was $>80 \%$ of predicted $(p=0.01)$, whereas the Cox regression model showed that the former were 2.6 times as likely to have an exacerbation over a 2-year period as were the latter ( $p=$ 0.02). Conclusions: In Brazil, the 6MWD can predict acute exacerbations of COPD over a 2-year period. The risk of experiencing an acute exacerbation of COPD within 2 years is more than twice as high in patients in whom the 6MWD is $\leq 80 \%$ of predicted.
\end{abstract}

Keywords: Pulmonary disease, chronic obstructive; Risk groups; Exercise.

\section{INTRODUCTION}

According to the Global Initiative for Obstructive Lung Disease (GOLD), an exacerbation of COPD is defined as an acute event characterized by worsening from baseline in respiratory symptoms-including increased lung hyperinflation, reduced airflow, dyspnea, and hypoxemia-requiring a change in regular medication.(1) Although exacerbations of COPD are common during the course of the disease, they should be prevented in order to avoid worsening of the pulmonary and systemic involvement characteristic of COPD.

Acute exacerbations of COPD commonly result in reduced lung function, ${ }^{(2)}$ reduced peripheral muscle strength,(3) reduced respiratory muscle strength, ${ }^{(4)}$ reduced physical activity in daily life, ${ }^{(5)}$ reduced exercise capacity $^{(6)}{ }^{(6)}$ inceased mortality, ${ }^{(7)}$ increased health care costs, ${ }^{(8,9)}$ and reduced health-related quality of life. ${ }^{(10)}$ Therefore, it is important to prevent exacerbations of COPD. Predictors of COPD exacerbations include lung function, a history of exacerbations, exercise capacity, and health status, ${ }^{(1,11)}$ all of which can contribute to improving the clinical management of patients with COPD.
Given that the six-minute walk test (6MWT) is simple, is easy to perform, is inexpensive, and has good responsiveness, ${ }^{(12,13)}$ it is widely used in order to assess functional exercise capacity and predict exacerbations of COPD. ${ }^{(14,15)}$ A six-minute walk distance (6MWD) of $<350 \mathrm{~m}$ has been employed as a predictor of COPD exacerbation. ${ }^{(14)}$ Given that the 6MWD is longer in individuals in Brazil than in those in other countries, ${ }^{(16)}$ the aforementioned 6MWD might not be applicable to COPD patients in Brazil, a different cut-off point therefore being required.

Although a cut-off point for the 6MWD has yet to be established in Brazil, previous studies have used a cutoff point of $80 \%$ of the predicted value. ${ }^{(17,18)}$ A cut-off point expressed as a percentage of the predicted value might be more appropriate for two reasons: 1 ) it takes into account individual patient characteristics; and 2) it prevents the introduction of an absolute value bias when it is applied to different populations, the 6MWD being longer in Brazil than in other countries. ${ }^{(16)}$

Individuals in whom the 6MWD is $>80 \%$ of predicted are considered to have preserved exercise capacity. To the best of our knowledge, there have been no studies examining the

Correspondence to:

Fabio Pitta. Rua Robert Koch, 60, Departamento de Fisioterapia, Vila Operária, CEP 86038-350, Londrina, PR, Brasil.

Tel.: 5543 3371-2477. E-mail: fabiopitta@uol.com.br

Financial support: This study received financial support from the Brazilian Conselho Nacional de Desenvolvimento Cientiffico e Tecnológico ICNPq, National Council fo Scientific and Technological Development) and the Coordenação de Aperfeiçoamento de Pessoal de Nive/ Superior (CAPES, Office for the Advancement of Higher Education). 
6MWD as a predictor of COPD exacerbations in patients in Brazil not participating in a rehabilitation program and not recently hospitalized, currently participating in a rehabilitation program and having recently been hospitalized being factors that influence the prediction of exacerbations. Therefore, the objective of the present study was to evaluate whether the 6MWD can predict acute exacerbations of COPD over a 2-year period in COPD patients in Brazil. Our hypothesis was that the risk of acute exacerbation of COPD over a 2-year period would be higher in patients in whom the 6MWD was $\leq$ $80 \%$ of the predicted value than in those in whom the 6MWD was $>80 \%$ of the predicted value.

\section{METHODS}

This was a retrospective observational study involving a convenience sample and including data collected in the 2010-2013 period regarding COPD patients who had been invited to participate in a rehabilitation program but for various reasons (including difficulties with transportation and lack of time) underwent the initial evaluation only; that is, they did not undergo physical training. The criteria for inclusion in the present study were as follows: having been diagnosed with COPD in accordance with the GOLD criteria(1); being clinically stable, i.e., having had no exacerbations in the last 3 months; having no comorbidities that could affect the tests performed; and having participated in no exercise training programs in the year prior to the study. The exclusion criteria were as follows: unavailable medical records; inability to contact patients or close relatives by telephone; and a 6MWD and pulmonary function test results characterizing outliers (i.e., values within \pm 2 SDs of the mean).

The present study was conducted in the Respiratory Therapy Research Laboratory of the State University at Londrina and at the Health Sciences Research Center of the University of Northern Paraná, both of which are located in the city of Londrina, Brazil, and was approved by the Human Research Ethics Committee of the State University at Londrina (Protocol no. 123/09). All patients gave written informed consent.

\section{Pulmonary function testing (spirometry)}

Spirometry was performed with a Pony ${ }^{\circledR}$ spirometer (Cosmed, Rome, Italy). All tests were performed in accordance with the American Thoracic Society and European Respiratory Society guidelines, ${ }^{(19)}$ and postbronchodilator values were used. The reference values for the Brazilian population were those established by Pereira et al. (20)

\section{MWT}

The 6MWT was performed in accordance with international guidelines by trained raters. ${ }^{(12)}$ Patients were instructed to walk in a 30-m corridor for $6 \mathrm{~min}$, receiving standard encouragement during the test. Two tests were performed, at least 30 min apart, the longer 6MWD being used for analysis. Blood pressure,
$\mathrm{HR}$, and $\mathrm{SpO}_{2}$, as well as dyspnea and fatigue (as assessed by the modified Borg scale), were assessed before and after each test.

For all analyses, patients were divided into two groups: that of those in whom the 6MWD was $>80 \%$ of the distance predicted by applying a formula proposed by Britto et al. (equation 1) (21); and that of those in whom the 6 MWD was $\leq 80 \%$ of the predicted distance. ${ }^{(17,18)}$

\section{Evaluation of exacerbations}

The occurrence of exacerbations of COPD within 2 years of the evaluation of exercise capacity by the 6MWT was determined by analyzing medical records and contacting patients by telephone. We investigated the occurrence of acute exacerbations of COPD independently of the number of events occurring during the study period. An exacerbation of COPD was defined as a worsening of respiratory symptoms that is beyond normal day-to-day variations and that requires a change in regular medication, although it does not require hospitalization. ${ }^{(1)}$

\section{Statistical analysis}

All statistical analyses were performed with the IBM SPSS Statistics software package, version 20.0 (IBM Corporation, Armonk, NY, USA). Normality of the data was tested by the Shapiro-Wilk test, and the results were described as means and standard deviations. The two groups of patients were compared by unpaired t-test. The log-rank test and the Kaplan-Meier method were used in order to compare the groups in terms of the occurrence of exacerbations. Cox regression adjusted for confounding variables (gender, body mass index-BMI-and lung function) was used in order to determine whether a $6 \mathrm{MWD}=80 \%$ of predicted was able to predict exacerbations over a 2-year follow-up period. The level of significance was set at $p<0.05$.

\section{RESULTS}

Our convenience sample consisted of 67 patients. However, 9 were excluded because we were unable to gain access to all relevant information and 8 were excluded because they were considered to be outliers regarding pulmonary function test results, the 6MWD, or a combination of the two. Of the 50 patients who remained in the study (Table 1), 5 died (4 from pneumonia and 1 from acute myocardial infarction) and 25 experienced exacerbations during the 2-year follow-up period. With regard to functional exercise capacity, the mean 6MWD was $469 \pm 60 \mathrm{~m}$ (86 \pm $10 \%$ of predicted).

There were no significant differences between the patients in whom the 6MWD was $>80 \%$ of predicted $(n=33)$ and those in whom the 6MWD was $\leq 80 \%$ of predicted ( $n=17$ ) regarding age, gender, height, weight, BMI, or lung function.

The Kaplan-Meier curves (Figure 1) showed a significant difference ( $p=0.01$ ) between the two groups of patients regarding the occurrence of 
exacerbations, which were more common in those in whom the 6MWD was $\leq 80 \%$ of predicted than in those in whom the 6MWD was $>80 \%$ of predicted. This difference was more pronounced from the tenth month of follow-up onward.

The Cox regression model showed that, even after adjustment for confounding variables, patients in whom the $6 \mathrm{MWD}$ is $\leq 80 \%$ of predicted are 2.6 times more likely to experience exacerbations over the course of 2 years than are those in whom the 6MWD is $>80 \%$ of predicted ( $95 \% \mathrm{CI}: 1.1-5.8 ; \mathrm{p}=0.02)$.

\section{DISCUSSION}

The results of the present study show that, in Brazil, COPD patients in whom the 6MWD is $<80 \%$ of the predicted value are more than twice as likely to experience exacerbations within 2 years after the 6MWT as are those whose exercise capacity is preserved.

In addition to normal day-to-day variations in the natural course of the disease, patients with COPD experience exacerbations requiring at least 90 days for a return to baseline health status; in some cases, recovery is incomplete even after 90 days. ${ }^{(22)}$ Given that morbidity and mortality are high in patients with COPD, it is extremely important to prevent and predict acute exacerbations in order to avoid loss of lung function and the high costs of treatment.

Previous studies ${ }^{(14,15)}$ have shown that the 6MWD can predict exacerbations in patients with COPD. Andrianopoulos et al. ${ }^{(15)}$ recommended that a 6MWD of $375 \mathrm{~m}$ be used as a cut-off point to predict a higher risk of COPD exacerbation over a 3-year follow-up period. However, that cut-off point might not be appropriate for the Brazilian population, given that the 6MWD is greater in Brazil than in other countries.

In a study conducted in Brazil,(23) multidimensional indices were used in order to predict COPD exacerbations, including the Body mass index, airflow Obstruction, Dyspnea, and Exercise capacity (BODE) index, ${ }^{(24)}$ which is more comprehensive than the 6MWD alone. Given that the BODE index assesses different outcomes (BMI, FEV ${ }_{1}$, dyspnea-as assessed by the modified Medical Research Council scale-and the 6MWD), it is more difficult to perform and it takes longer to be calculated, therefore being more difficult to use in clinical practice. The present study showed that, in COPD patients in Brazil, the 6MWD alone can predict acute exacerbations of the disease. Casanova et al.(16) showed that the 6MWD is longer in healthy individuals in Brazil than in those in other countries, whereas Pitta et al. ${ }^{(25)}$ showed that daily physical activity levels are higher in COPD patients in Brazil than in those in Europe. The fact that daily physical activity levels in the Brazilian population correlate, albeit moderately, with functional exercise capacity ${ }^{(26)}$ reinforces the need to adopt specific indices for different populations.

In the present study, the Kaplan-Meier curves showed a significant difference between the patients in whom the 6MWD was $>80 \%$ of the predicted value and those in whom the 6MWD was $\leq 80 \%$ of the predicted value regarding the exacerbation rate. This finding is consistent with the literature, ${ }^{(15)}$ and this difference apparently becomes more pronounced after the tenth month of follow-up.

To the best of our knowledge, this is the first study to evaluate the role of the 6MWD in predicting exacerbations of COPD in patients in Brazil not participating in a rehabilitation program. Marino et al. ${ }^{(27)}$ demonstrated that the 6MWD and dependent covariates (BMI and lean body mass) are associated with risk of exacerbation; however, the fact that the aforementioned study involved patients in Brazil participating in a physical therapy program constitutes a limitation, given that physical activity prevents exacerbations. ${ }^{(1)}$

Table 1. General characteristics of the patients.

\begin{tabular}{|c|c|c|c|}
\hline Characteristic & $\begin{array}{c}6 \mathrm{MWD} \leq 80 \% \text { of predicted } \\
(\mathrm{n}=17)\end{array}$ & $\begin{array}{c}\text { 6MWD }>80 \% \text { of predicted } \\
(n=33)\end{array}$ & $\begin{array}{l}\text { Study sample (n } \\
=50 \text { ) }\end{array}$ \\
\hline Gender (M/F) & $10 / 7$ & $16 / 17$ & $26 / 24$ \\
\hline Age, years & $70 \pm 7$ & $66 \pm 7$ & $67 \pm 7$ \\
\hline $\begin{array}{l}\mathrm{BMI}, \mathrm{kg} / \mathrm{m}^{2} \\
\text { GOLD, I/II/III/IV }\end{array}$ & $\begin{array}{c}22 \pm 5 \\
0 / 3 / 5 / 9\end{array}$ & $\begin{array}{c}25 \pm 4 \\
1 / 11 / 16 / 5\end{array}$ & $\begin{array}{c}24 \pm 5 \\
1 / 14 / 21 / 14\end{array}$ \\
\hline $\mathrm{FEV}_{1}, \%$ of predicted & $37 \pm 19$ & $43 \pm 13$ & $41 \pm 15$ \\
\hline $\begin{array}{l}\mathrm{FEV}_{1} / \mathrm{FVC}, \% \\
6 \mathrm{MWD}, \mathrm{m} \\
6 \mathrm{MWD}, \% \text { of predicted }\end{array}$ & $\begin{array}{c}52 \pm 11 \\
374 \pm 73 \\
73 \pm 13\end{array}$ & $\begin{array}{c}52 \pm 9 \\
495 \pm 55^{*} \\
95 \pm 12^{*}\end{array}$ & $\begin{array}{l}52 \pm 10 \\
454 \pm 84 \\
84 \pm 15\end{array}$ \\
\hline $\begin{array}{l}\text { Pre-6MWT Borg dyspnea } \\
\text { Post-6MWT Borg dyspnea } \\
\text { Pre-6MWT Borg fatigue } \\
\text { Post-6MWT Borg fatigue } \\
\text { Pre-6MWT HR, bpm } \\
\text { Post-6MWT HR, bpm } \\
\text { Pre-6MWT SpO }, \% \\
\text { Post-6MWT } \mathrm{SpO}_{2}, \%\end{array}$ & $\begin{array}{c}1 \pm 1 \\
3 \pm 2 \\
1 \pm 2 \\
3 \pm 2 \\
85 \pm 17 \\
106 \pm 15 \\
92 \pm 3 \\
92 \pm 3\end{array}$ & $\begin{array}{c}1 \pm 1 \\
3 \pm 2 \\
1 \pm 1 \\
3 \pm 2 \\
84 \pm 17 \\
115 \pm 13 \\
94 \pm 2 \\
92 \pm 3\end{array}$ & $\begin{array}{c}1 \pm 1 \\
3 \pm 2 \\
1 \pm 1 \\
3 \pm 2 \\
84 \pm 17 \\
112 \pm 14 \\
94 \pm 3 \\
92 \pm 3\end{array}$ \\
\hline
\end{tabular}

6MWT: six-minute walk test; 6MWD: six-minute walk distance; M: male; F: female; BMI: body mass index; GOLD:

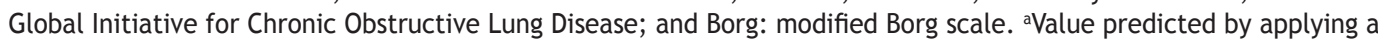
formula developed by Britto et al. ${ }^{(21) *} \mathrm{p}<0.05$ vs. $6 \mathrm{MWD}<80 \%$ of predicted. 


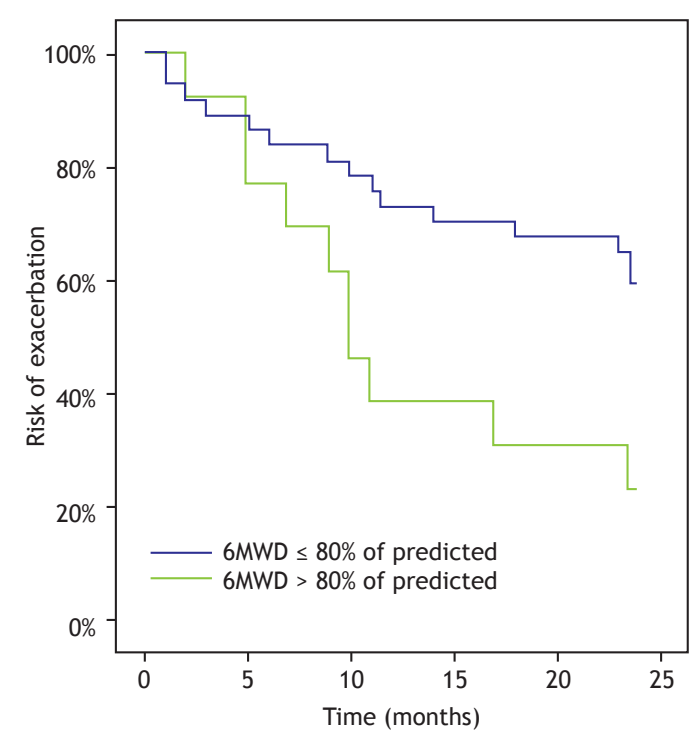

Figure 1. Kaplan-Meier curves for the risk of COPD exacerbation in patients in Brazil in whom the six-minute walk distance (6MWD) was $>80 \%$ of the predicted value or $\leq 80 \%$ of the predicted value.

Zanoria et al.(14) used a 6MWD of $<350 \mathrm{~m}$ as a cut-off point for predicting mortality in patients with
COPD. ${ }^{(28)}$ The authors showed that patients in whom the 6MWD was $<350 \mathrm{~m}$ were 8.4 times more likely to experience exacerbations of COPD over a 1-year period. The present study proposes a new cut-off point for the 6MWD (i.e., a 6MWD $\leq 80 \%$ of the predicted value) as a predictor of exacerbation risk in COPD patients in Brazil.

Potential limitations of the present study include the methodology used in order to collect data on exacerbations of COPD and the power of Cox regression. However, great care was taken in exploring the data in order to ensure the accuracy of the information obtained. Other limitations include the fact that this was a retrospective study involving a convenience sample and the fact that we did not investigate the frequency of exacerbations; we simply determined whether exacerbations of COPD had occurred during the study period. Prospective studies and similar studies involving larger samples might contribute to the established literature and to clinical practice.

In conclusion, the 6MWD can predict COPD exacerbations occurring over a 2-year period in patients in Brazil. The risk of experiencing an exacerbation of COPD within 2 years is more than twice as high in patients in whom the 6MWD is $\leq 80 \%$ of predicted.

\section{REFERENCES}

1. Global Initiative for Chronic Obstructive Lung Disease [homepage on the Internet]. Bethesda: Global Initiative for Chronic Obstructive Lung Disease. [cited 2015 Sep 15]. Global strategy for the diagnosis, management, and prevention of COPD - 2015. Available from: http:// goldcopd.org/global-strategy-diagnosis-management-preventioncopd-2015/

2. Nussbaumer-Ochsner $Y$, Rabe KF. Systemic manifestations of COPD. Chest. 2011;139(1):165-73. https://doi.org/10.1378/chest.10-1252

3. Spruit MA, Gosselink R, Troosters T, Kasran A, Gayan-Ramirez G, Bogaerts $P$, et al. Muscle force during an acute exacerbation in hospitalised patients with COPD and its relationship with CXCL8 and IGF-I. Thorax. 2003;58(9):752-6. https://doi.org/10.1136/ thorax.58.9.752

4. Mesquita R, Donária L, Genz IC, Pitta F, Probst VS. Respiratory muscle strength during and after hospitalization for COPD exacerbation. Respir Care. 2013;58(12):2142-9. https://doi. org/10.4187/respcare.02393

5. Pitta F, Troosters T, Probst VS, Spruit MA, Decramer M, Gosselink R. Physical activity and hospitalization for exacerbation of COPD. Chest. 2006;129(3):536-44. https://doi.org/10.1378/chest.129.3.536

6. Cote CG, Dordelly LJ, Celli BR. Impact of COPD exacerbations on patient-centered outcomes. Chest. 2007;131(3):696-704. https://doi. org/10.1378/chest.06-1610

7. Soler-Cataluña JJ, Martínez-Garcia MA, Román Sánchez P, Salcedo E, Navarro M, Ochando R. Severe acute exacerbations and mortality in patients with chronic obstructive pulmonary disease. Thorax. 2005;60(11):925-31. https://doi.org/10.1136/thx.2005.040527

8. Burge S, Wedzicha JA. COPD exacerbations: definitions and classifications. Eur Respir J Suppl. 2003;41:46s-53s. https://doi.org $/ 10.1183 / 09031936.03 .00078002$

9. Maddocks M, Kon SS, Singh SJ, Man WD. Rehabilitation following hospitalization in patients with COPD: can it reduce readmissions? Respirology. 2015;20(3):395-404. https://doi.org/10.1111/resp.12454

10. Kon SS, Canavan JL, Jones SE, Nolan CM, Clark AL, Dickson MJ, et al. Minimum clinically important difference for the COPD Assessment Test: a prospective analysis. Lancet Respir Med. 2014;2(3):195-203. https://doi.org/10.1016/S2213-2600(14)70001-3

11. Hurst JR, Vestbo J, Anzueto A, Locantore N, Mullerova H, TalSinger $R$, et al. Susceptibility to exacerbation in chronic obstructive pulmonary disease. N Engl J Med. 2010;363(12):1128-38. https://doi. org/10.1056/NEJMoa0909883

12. ATS Committee on Proficiency Standards for Clinical Pulmonary Function Laboratories. ATS statement: guidelines for the six-minute walk test. Am J Respir Crit Care Med. 2002;166(1):111-7. https://doi. org/10.1164/ajrccm.166.1.at1102

13. Pinto-Plata VM, Cote C, Cabral H, Taylor J, Celli BR. The 6-min walk distance: change over time and value as a predictor of survival in severe COPD. Eur Respir J. 2004;23(1):28-33. https://doi.org/10.118 3/09031936.03.00034603

14. Zanoria SJ, ZuWallack R. Directly measured physical activity as a predictor of hospitalizations in patients with chronic obstructive pulmonary disease. Chron Respir Dis. 2013;10(4):207-13. https://doi. org/10.1177/1479972313505880

15. Andrianopoulos V, Wouters EF, Pinto-Plata VM, Vanfleteren LE, Bakke PS, Franssen FM, et al. Prognostic value of variables derived from the six-minute walk test in patients with COPD: Results from the ECLIPSE study. Respir Med. 2015;109(9):1138-46. https://doi. org/10.1016/j.rmed.2015.06.013

16. Casanova C, Celli BR, Barria P, Casas A, Cote C, de Torres JP, et al. The 6-min walk distance in healthy subjects: reference standards from seven countries. Eur Respir J. 2011;37(1):150-6. https://doi org/10.1183/09031936.00194909

17. Moreira GL, Donária L, Furlanetto KC, Paes T, Sant'Anna T, Hernandes NA, et al. GOLD B-C-D groups or GOLD II-III-IV grades: Which one better reflects the functionality of patients with chronic obstructive pulmonary disease? Chron Respir Dis. 2015;12(2):10210. https://doi.org/10.1177/1479972315573528

18. Soaresa MR, Pereira CA. Six-minute walk test: reference values for healthy adults in Brazil. J Bras Pneumol. 2011;37(5):576-83.

19. Miller MR, Hankinson J, Brusasco V, Burgos F, Casaburi R, Coates A, et al. Standardisation of spirometry. Eur Respir J. 2005;26(2):319-38. https://doi.org/10.1183/09031936.05.00034805

20. Pereira CA, Sato T, Rodrigues SC. New reference values for forced spirometry in white adults in Brazil. J Bras Pneumol. 2007;33(4):397406. https://doi.org/10.1590/S1806-37132007000400008

21. Britto RR, Probst VS, de Andrade AF, Samora GA, Hernandes $N A$, Marinho PE, et al. Reference equations for the six-minute walk distance based on a Brazilian multicenter study. Braz $J$ 
Phys Ther. 2013;17(6):556-63. https://doi.org/10.1590/S141335552012005000122

22. Seemungal TA, Donaldson GC, Bhowmik A, Jeffries DJ, Wedzicha JA. Time course and recovery of exacerbations in patients with chronic obstructive pulmonary disease. Am J Respir Crit Care Med. 2000;161(5):1608-13. https://doi.org/10.1164/ajrccm.161.5.9908022

23. Faganello MM, Tanni SE, Sanchez FF, Pelegrino NR, Lucheta PA, Godoy I. BODE index and GOLD staging as predictors of 1-year exacerbation risk in chronic obstructive pulmonary disease. Am J Med Sci. 2010;339(1):10-4. https://doi.org/10.1097/ MAJ.0b013e3181bb8111

24. Celli BR, Cote CG, Marin JM, Casanova C, Montes de Oca M, Mendez RA, et al. The body-mass index, airflow obstruction, dyspnea, and exercise capacity index in chronic obstructive pulmonary disease. $N$ Engl J Med. 2004;350(10):1005-12. https://doi.org/10.1056/ NEJMoa021322
25. Pitta F, Breyer MK, Hernandes NA, Teixeira D, Sant'Anna TJ Fontana $A D$, et al. Comparison of daily physical activity between COPD patients from Central Europe and South America. Respir Med. 2009;103(3):421-6. https://doi.org/10.1016/j.rmed.2008.09.019

26. Hernandes NA, Teixeira Dde C, Probst VS, Brunetto AF, Ramos EM, Pitta F. Profile of the level of physical activity in the daily lives of patients with COPD in Brazil. J Bras Pneumol. 2009;35(10):949-56. https://doi.org/10.1590/S1806-37132009001000002

27. Marino DM, Marrara KT, Arcuri JF, Candolo C, Jamami M, D Lorenzo VA. Determination of exacerbation predictors in patients with COPD in physical therapy - a longitudinal study. Braz $J$ Phys Ther. 2014;18(2):127-36. https://doi.org/10.1590/S141335552012005000146

28. Cote CG, Casanova C, Marín JM, Lopez MV, Pinto-Plata V, de Oca $\mathrm{MM}$, et al. Validation and comparison of reference equations for the 6-min walk distance test. Eur Respir J. 2008;31(3):571-8. https://doi. org/10.1183/09031936.00104507 